\title{
STUDIES ON THE EFFECT OF THE ACTION OF DIGITALIS ON THE OUTPUT OF BLOOD FROM THE HEART
}

\section{The Effect on the Output of the Dog's Heart in Heart-Lung Preparations ${ }^{1}$}

\author{
By ALFRED E. COHN AND J. MURRAY STEELE
}

(From the Hospital of the Rockefeller Institute for Medical Research, New York)

(Received for publication May 6, 1932)

A satisfactory solution of the problem concerning the effect of giving digitalis, especially on the volume output of the heart, but of other problems concerning its action, is still outstanding. Difficulties in the way of complete understanding depend, it seems, on the circumstances in which digitalis is administered. Among these are the species of animal which is studied and the state of the heart, whether healthy or diseased. The value of digitalis as a therapeutic agent, being on many accounts a constant source of concern, is viewed as being involved in these issues. Discussion is of ten confused, action of the drug and the beneficence of that action being regarded as the same things. This inference need not necessarily be correct. The pulse rate may be lowered, the blood pressure raised, the excretion of water unchanged, the volume output of blood from the heart either decreased or increased; the effect of not one of these actions can supply a clue, $a$ priori, to whether giving this agent is advisable. In terms of no one of these functions can its value or benefit be described. The situation is different in an infectious fever. Barring the artificial lowering of temperature as a single effect without influence on the general course of the illness, defervescence is usually, and perhaps justly, regarded as a sign of value.

If the success of an agent cannot be measured in terms of a "test" of its efficacy, how can it be measured? Is it necessary to rely on the report of its effect by patients or is there something in the totality of their demeanor which permits the drawing of a relevant inference? In whatever way this phase of the matter is decided, an outstanding consideration is this, that a judgment is desirable which is not dependent on the measurement of some function, involved no doubt in the total action, but yet not characteristic of a result regarded as satisfactory. In the case of giving digitalis for example, patients may, conceivably, report

1 A preliminary report of these researches was read before the Association of American Physicians. (Trans. Assoc. Am. Phys., 1931, xlvi, 71.) 
"improvement" on taking the drug. Under these circumstances, if we associate with improvement increase, for example, in the volume output of blood from the heart and learn, unfortunately, that decrease has taken place, we face a dilemma; the output has decreased but the patient is better. To know the volume output is, for the present, an inadequate guide. The problem is not solved by turning from methods of analysis to others much coarser and not susceptible to detailed examination; that way would be the negation of method. Further study is needed to attempt to discover a form of analysis which tells us what we desire to learn, perhaps a method which measures the effect of an agent on the behavior of the entire individual. Knowledge may consist, obviously, in terms either of the whole or of one of its analyzed parts. But the balance between what the part can tell and what the whole describes is delicate; what must, it seems, not be upset is judgment of the whole, in favor of a part. Digitalis, in short, should be given if patients improve, even if, were this the case, the volume output of blood decreases as the result of taking it.

The fruitful experiments of Harrison and Leonard (1) have made it clear that the volume output of blood from the heart can be reduced by digitalis. Important as this information is, suggesting, as it does, a new point of view from which to weigh the action of digitalis, a wide generalization based on this phenomenon seems inadmissible. For there may be, as has turned out to be a fact, a difference between hearts which are normal in size and hearts which are enlarged. ${ }^{2}$ If an effect of digitalis is to decrease the size of all hearts, small as well as large, this result may still make a difference in the subsequent output of hearts initially normal and of hearts initially enlarged. But aside from size, there might be involved, in enlarged, diseased hearts, an additional factor. That this might be the situation was suggested in a report of experiments which confirmed those of Harrison and Leonard.

In the experiments of Cohn and Stewart (2), decreased output of the normal heart as a consequence of the action of digitalis was described as a fact, associated with decrease in the size of the heart. The effect on output was ascribed to two factors, one on the size of the heart which was designated tone, and a second, an effect on contraction. Of the two, the effect on size predominated. This explanation Dock and Tainter (3) regard as unsatisfactory because it failed to take into account "all the known and established actions of the drug on the circulation and does not correlate the latter with factors determining cardiac output." They urged the view that in any judgment of the action of digitalis on the vol-

2 The word enlarged is used, not to obscure the difference between dilatation and hypertrophy, but to suggest that of these conditions the one which is present is not always known. The two aspects of enlargement can, furthermore, not always be separated. 
ume output it is not enough to study only the behavior of the heart; its effect on the blood vessels must also be estimated. The fact that in their experiments "a fall in venous pressure regularly accompanied the diminished cardiac output" they regard as "convincing evidence that the change in blood flow was a result of peripheral, and not cardiac, actions of the drug" (Conclusion 3) (3). Tainter and Dock (4) showed later that "the fall in right auricular pressure, after giving digitalis to dogs with the hepatic circulation intact, was due to diminished venous return flow, and ultimately to an accumulation of blood in the splanchnic or portal region as a result of obstructed hepatic outflow (hepatic vein constriction).

This mechanism adequately explains the diminution in cardiac output after digitalis, since a diminished venous return must result in deficient cardiac filling. This conclusion agrees with that of our previous paper" (Conclusion 3) (4).

If both the heart and the peripheral circulation are, as is well known, affected by the action of digitalis, the problem in the case of normal hearts is this; how far is the effect of digitalis on the volume output exercised on the heart itself and how far on the amount of the venous return?

That there is a difference in behavior between enlarged hearts and hearts of normal size, and that this difference is of deciding importance, will be shown in these studies. What the relative share is of heart and periphery will also be discussed.

There is already evidence of the course of events in heart-lung preparations where a digitalis body is given to the heart in an enfeebled state. Hearts that were enlarged or failing have been studied by Anitschkow and Trendelenburg (5) who showed that by increasing the inflow (raising the venous reservoir in heart-lung preparations), the output, after the heart was made to fail was much greater than before if strophanthin were injected, and that corresponding to this effect the pressure in the right auricle fell. Bijlsma, and Roessingh (6) noticed that in heart-lung preparations, when the heart was in process of dilating, it became smaller after giving strophanthin, though the resistance, the arterial pressure and the volume output remained unchanged. Plant (7) also has shown that when strophanthin is given to a failing heart, poisoned previously during two to three weeks with phosphorus so that it is the subject of fatty degeneration, the volume output increased, the pressure in the inferior vena cava decreased; and the amplitude of contraction increased as did the blood pressure.

Here then are three sets of experiments, based on the study of failing hearts, all enlarged, in heart-lung preparations, in which increase in output went parallel with fall in venous pressure (Anitschkow and Trendelenburg, and Plant) and in which decrease in the size of the heart took place (Bijlsma and Roessingh). The effects were transient (Plant), the initial situation having been restored in 20 minutes. 
The phenomena which are now reported were observed in hearts of heart-lung preparations, during a period of several hours until the time when complete failure of the preparation seemed imminent. As is well known, such preparations permit the control and measurement of several functions of which the circulation depends-the venous pressure, the volume output, the arterial resistence, the temperature. Obviously, hearts in heart-lung preparations cannot be regarded as fresh, or normal, or natural, due to the unwonted manipulations to which they have been exposed and also to the fact that they have been deprived of some of their extrinsic nerves. We do not, as a matter of fact, so regard them. Evidence that such hearts should not be considered fresh may be inferred from the fact that under the influence of digitalis, the minute output, unlike its effect in natural preparations and without regard to what ultimately will be held to be the mechanism, has not been seen to decrease, irrespective of the volume of the inflow.

For these experiments dogs weighing from 10 to 15 kilograms were used. Heart-lung preparations were made according to the general technique of Knowlton and Starling (8). The arrangements were varied, as will be pointed out, to suit the purposes of these experiments. Chloralose in physiological salt solution, neutralized by the addition of sodium hydroxide, served as anesthetic, and was injected intravenously usually in amounts of 0.1 gram per kilogram of body weight, but sometimes of 0.2 gram and rarely an addition of 0.5 gram. No morphine was given.

Blood for the experiment was secured from a second dog. Heparin, $5.0 \mathrm{mgm}$. diluted in $100 \mathrm{cc}$. normal salt solution was injected first into a femoral vein; then, under local, novocaine, anesthesia, the blood required was withdrawn from the carotid artery. To complete the process of bleeding, light ether anesthesia was administered.

The dog lay in the lower half of a box. On opening the chest, ventilation was maintained by a Starling pump. When the preparation was complete, a lid closed the box which was then made airtight. Air in an amount sufficient to create the desired level of negative pressure was then removed by a large piston pump. To vary the degree of negative pressure and by so doing to secure motions of the lungs, air was allowed to enter the chamber from a 3 liter rubber bag $(R B)$ through a valve $(V$, Fig. 1) the opening and shutting of which was managed automatically by the motions of the pump. The pressure in the box varied between -2 $\mathrm{cm}$. and $-4 \mathrm{~cm}$. water during expiration (shutting of the piston) and between $-12 \mathrm{~cm}$. and $-15 \mathrm{~cm}$. during inspiration. In normal animals the range in the intact pleural cavity is between $-2 \mathrm{~cm}$. and $-12 \mathrm{~cm}$. The mechanism of the box was designed to simulate that of respiration in the normal chest.

Certain details in technique are described: 


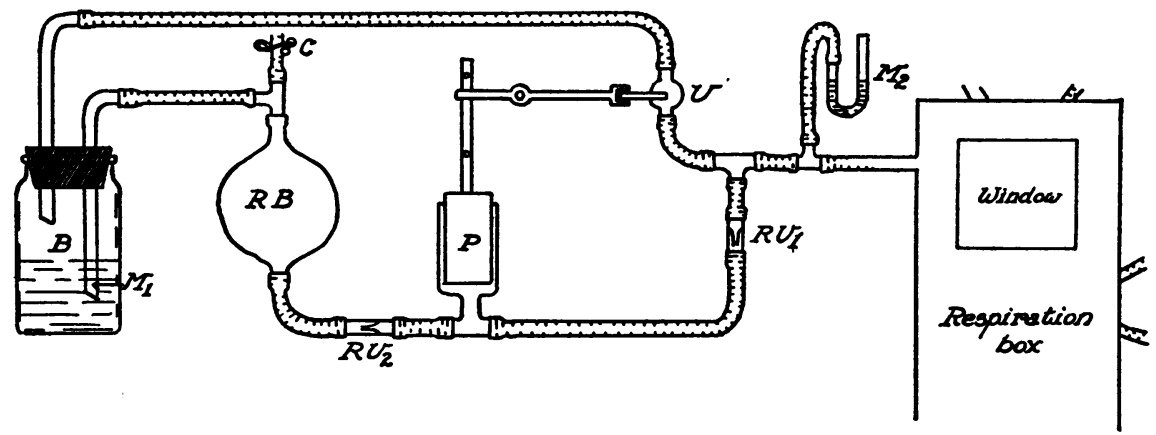

Fig. 1. This Diagram Shows the Arrangement of the System Used in Artificial Respiration in the Heart-Lung Preparation The details are described in the text.

1. An upstroke in the pump $(P)$ (capacity 4 liters) drew air from the box through the valve $\left(R V_{1}\right)$, excluding at the same time, by closing the valve $(V)$, that part of the circuit between valve $(V)$ and valve $\left(R V_{2}\right)$. A downstroke of the pump sent air through valve $\left(R V_{2}\right)$, a rubber bag $(R B)$, a water manometer $\left(M_{1}\right)$ and so back to the box through valve $(V)$, which had meanwhile been opened by the downstroke of the pump. A leak in the system was detected by ballooning of the bag $(R B)$, distension of which could be relieved by opening a cock $(C)$. The pressure in the system could be modified by the level of water in the bottle $(B)$. A manometer $\left(M_{2}\right)$ indicated changes in pressure in the box. By bubbling through water (in bottle $B$ ), the air in the system was kept moist.

2. When changes in the size of the heart were measured it was enclosed in a glass oncometer (Henderson) supplied with a rubber diaphragm, in which a hole was made, fitted snugly to the auriculoventricular groove (Figure 2). The oncometer was connected by pressure tubing with a volume recorder. At first a piston recorder (Huerthle) was used, next a cylindrical spirometer and finally, and also most satisfactorily, a Gad spirometer. The record of changes was inscribed on smoked paper.

3. The mean blood pressure in the brachiocephalic artery was recorded on the same smoked paper by a mercury manometer; that in the right auricle by a water manometer.

4. Peripheral resistance was provided in the usual manner (Knowlton and Starling (8)). Two resistance sleeves were placed in parallel in case of accident. The constancy of this system was checked by frequent readings of a mercury manometer.

5. The volume output was measured in a graduated cylinder, $50 \mathrm{ccm}$. or $100 \mathrm{ccm}$. being allowed to flow in on turning a three-way stopcock, the time required being taken by a stop-watch. Since the stop-watch was in an electric circuit the duration of the period was recorded on the smoked paper.

6. The height of the head of pressure of the blood flowing into the heart was kept constant. The reservoir was a flexible rubber bag immersed in a large jar of water (9). Through a tube of large bore $\left(1^{\prime \prime}\right)$ water in the beaker was displaced and passed freely to a bottle suspended by rubber, when blood in the reservoir exceeded a previous volume; conversely, decrease in the volume of blood in the reservoir invited a return flow of water into the beaker. The level of fluid once set remained, therefore, constant. By a rack and pinion, the height of this unit was easily adjusted. 
7. A stopcock, with large bore, was placed between the reservoir and the right auricle. A dial showing divisions mounted on the housing, and a pointer sealed to the cock, permitted the repetition of a given setting. The inflow could accordingly be reduced, simulating constriction of the veins.

8. A thermometer, placed in the cannula inserted in the superior vena cava, indicated the temperature of the blood (not shown in the figure).

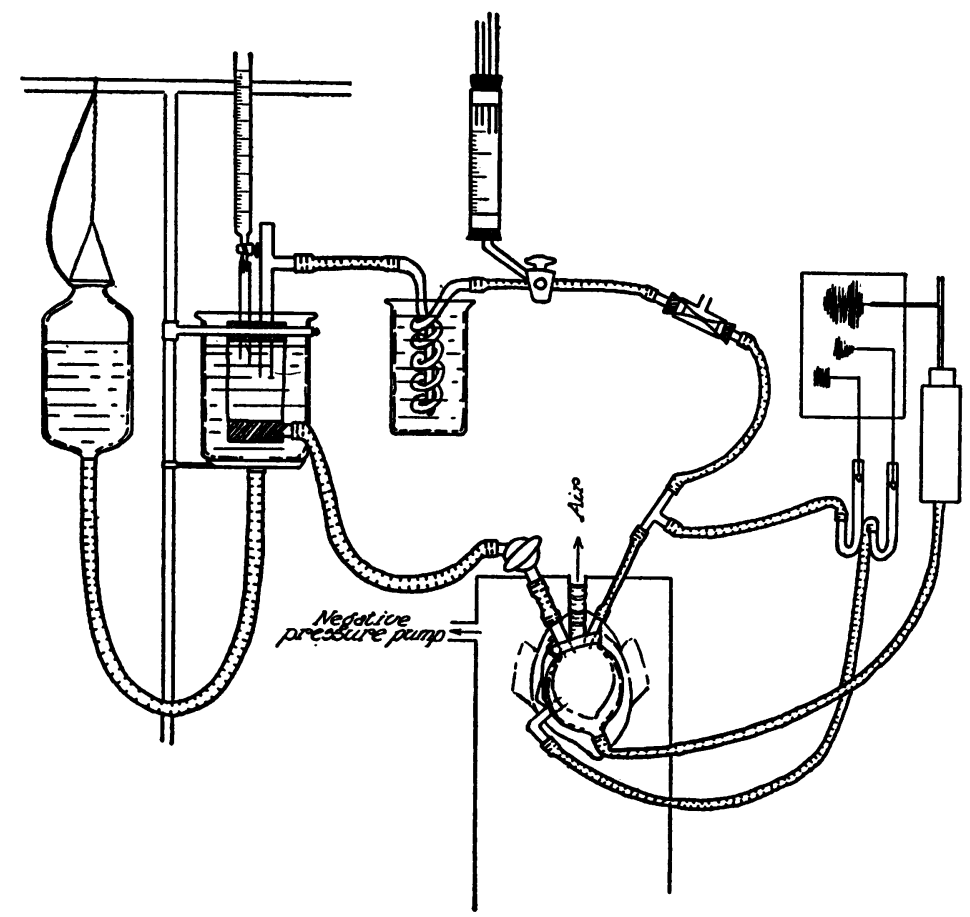

Fig. 2. This Diagram Shows the Arrangement of the System Used for the Circulation of Blood in the Heart-Lung Preparation

9. A solution of glucose and insulin flowed continuously into the venous reservoir from a graduated burette.

10. From a pet-cock, placed in the circuit just before the venous reservoir, blood was taken for analysis, and substances, such as digitalis (Digitan, Merck) were injected (not shown in the figure).

11. Time was recorded on the smoked paper at intervals of 1 second and 10 seconds.

\section{PROCEDURE}

Experiments of three types were performed. In the first, the ventilation was managed by the method of negative pressure-and without an oncometer about the heart. Although the degree of negative pressure which was exerted was comparable to that in the normal chest, when the bony thorax was divided and the edges were held apart, the lungs fell away from the heart and failed, therefore, to give it that support which normally protects it from the full force of negative pressure. How great 
this effect may be is observed in the record in which fluctuations due to this influence are clearly observed in the records of arterial and venous pressures. The latter ranged between $-3 \mathrm{~cm}$. and $+1 \mathrm{~cm}$. water. The second type of experiment was like the first except that an oncometer was placed over the heart. The result of this arrangement seemed to approach more closely that in a normal intact chest. The venous pressure ranged between $+2 \mathrm{~cm}$. and $+5 \mathrm{~cm}$. water. In this type is included a sub-group (5 experiments) in which was studied the effect of varying the volume of inflowing blood. In a third type, ventilation was positive, the Starling pump being employed. An oncometer was again fitted over the heart. This arrangement exhibited the least effect of respiration on the arterial and venous pressures and on the size of the heart. The venous pressures were the highest observed, ranging from $+5 \mathrm{~cm}$. to $+8 \mathrm{~cm}$. of water. They were lowest in the first group.

The arrangements employed, taken together, provided a range of venous pressures running from a level above to one below normal. Though the natural situation was absent, it has been possible, nevertheless, to test the action of digitalis under very varying conditions, within the range of which, many, even the normal ones must have been present. Though different in degree, the effects of giving digitalis tended, whatever the arrangements, in the same direction.

The results in each type of experiment are illustrated by describing one example in detail.

When the heart was not enclosed in an oncometer, it was the usual experience (Figure 3 ) to observe on transition to negative pressure that,

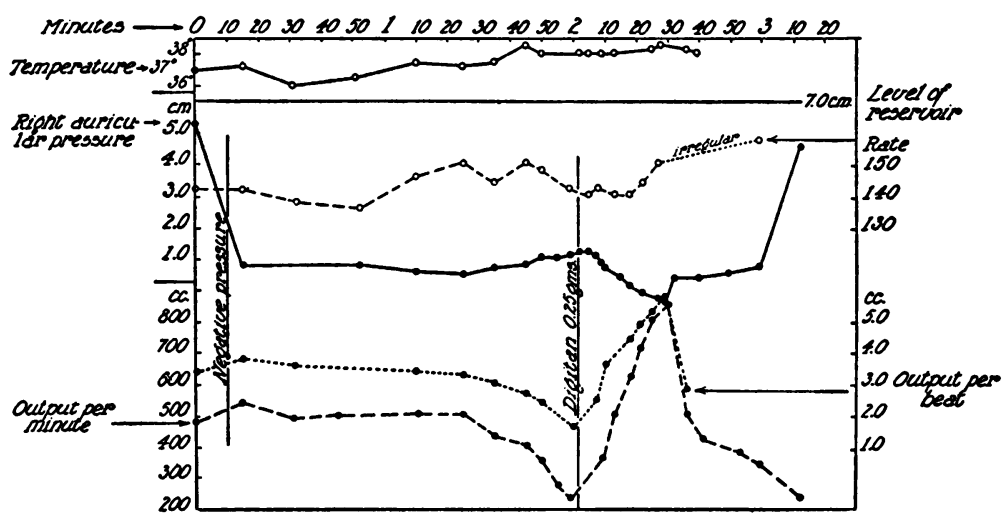

Fig. 3. The Curves are Shown of the Course of Events in EXPERIMENT NUMBER 44

The details are given in Table 1.

due no doubt to the pull exerted on the heart, for this effect did not appear when it was protected by an oncometer, pressure in the right auricle 
TABLE 1

March 5, 1931. Dog number 44. Weight of dog-10 kgm. Weight of heart-88 grams. Anesthesia-Chloralose-1.2 gram

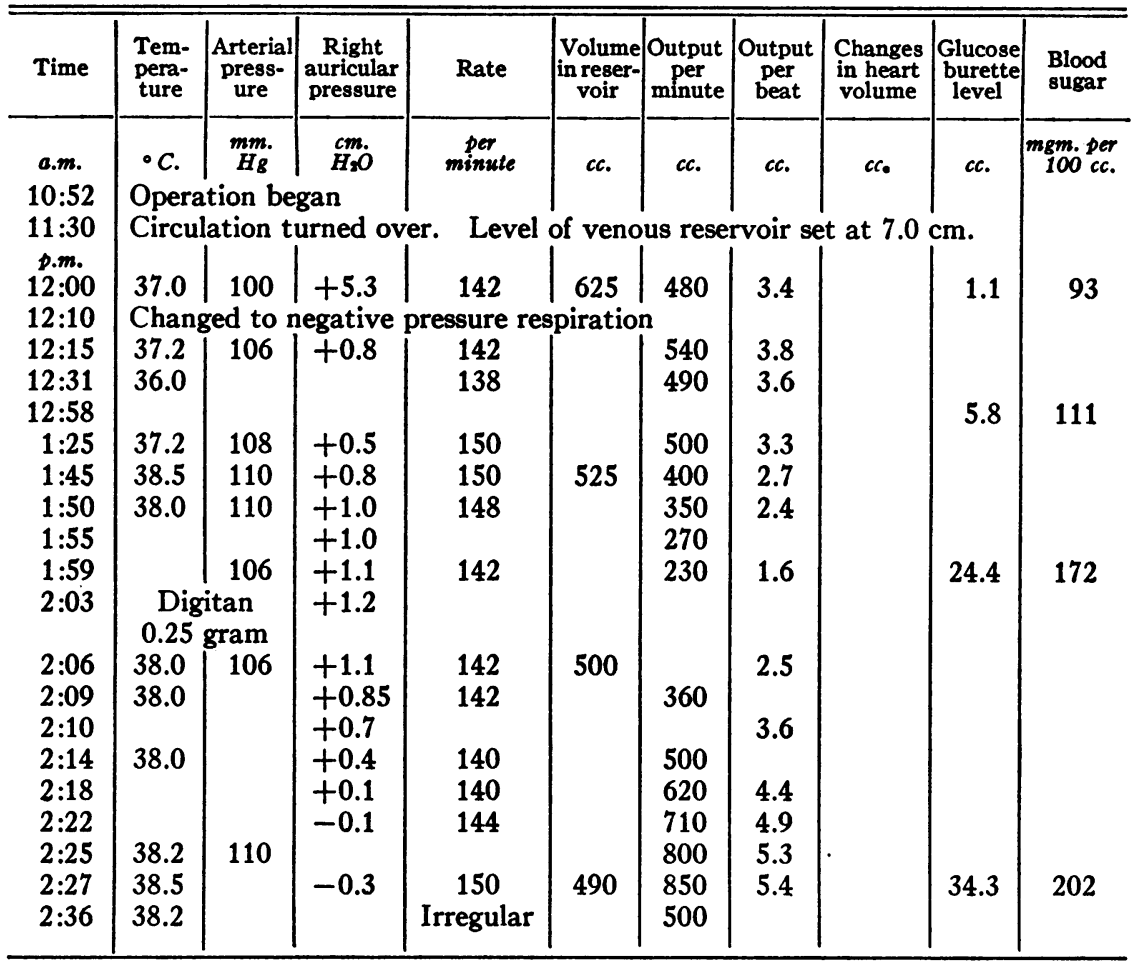

fell abruptly. At the same time the output of blood per minute and per beat from the heart increased slightly. Under negative pressure, the pressure in the right auricle remained practically stationary for about one hour. For about another half-hour it fell slightly, while the volume output decreased, also slightly. Then the heart began to fail, as is shown by the rise in pressure in the right auricle and in the sharp fall in volume output. The temperatures, meanwhile, underwent no important change. The arrangement of the "venous" reservoir remained constant throughout the experiment, the height being $7.0 \mathrm{~cm}$.; it seems doubtful whether the changes in the rate of the heart were influenced by the alterations in temperature which occurred. The heart was permitted to fail until, after two hours, the output per minute fell to about $225 \mathrm{ccm}$. Synchronously, the pressure in the right auricle rose slightly, but distinctly. Digitalis (in the form of digitan, 0.25 gram $^{8}$ ) was then injected. One

${ }^{3}$ This dose was calculated on the basis of 0.023 gram per kilogram. An amount having been calculated, as being suitable for intact animals, a smaller dose was given, taking the nature of the preparation into consideration. Later, doses still smaller were given. 
half-hour after injection, the output increased as much almost as four hundred per cent, and was greater by about fifty per cent $(550 \mathrm{ccm}$. to $825 \mathrm{ccm}$.) than the output just after the preparation was placed under negative pressure. During this period the pressure in the right auricle decreased to a point lower than during the early, steady period, falling so low indeed, that negative pressure was recorded; the ventricles were ejecting blood at least as fast as it was being supplied. An excess in the reservoir prevented exhaustion of the supply.

Too much digitalis, obviously, was injected, for the rate of the heart, having been steady for almost twenty minutes, increased rapidly; the rhythm then became quite irregular. The heart was irretrievably intoxicated. The output fell rapidly and in forty minutes was as small as just before digitan was given. Toward the end of the experiment, pressure in the right auricle rose.

The course of events in this experiment is clear enough. At first the preparation was sufficient. When it was near the point of death, the administration of digitalis revived it. Its effectiveness then was greater than it had been throughout the period of observation. Clear as is the demonstration that a dying heart can be revived, it was impossible to estimate what changes took place in its size, nor was it clear whether the heart was enlarged when digitalis was injected.

The next experiment (the second type) gives information on this point. The heart was enclosed in an oncometer. And it gives information also on another point. The stopcock, already described, was inserted in the tube leading to the right auricle. When the box in which the dog lay was subjected to negative pressure, that fall in pressure in the right auricle which took place when the heart lay bare, now, when an oncometer was fitted to it, failed to occur.

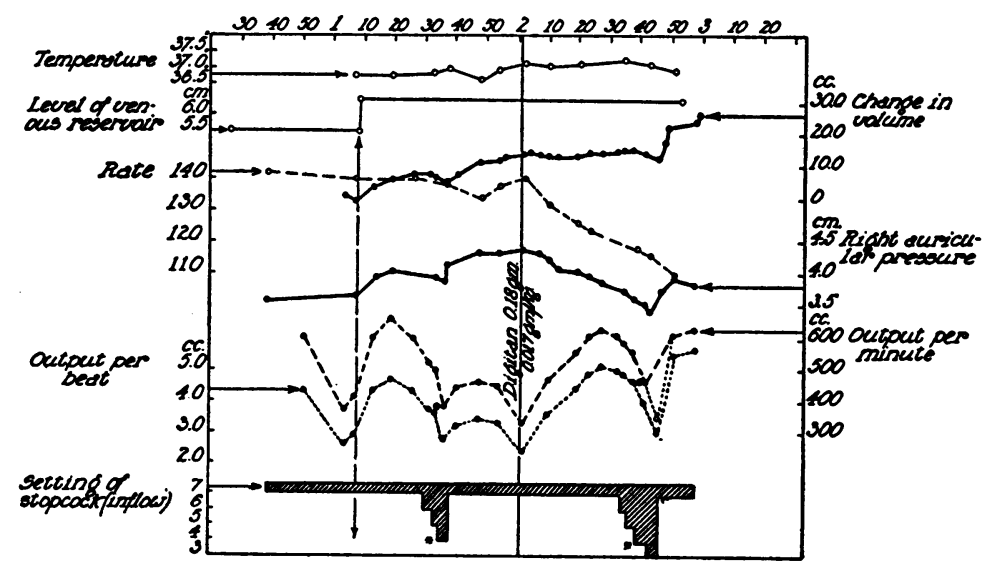

Fig. 4. The Curves are Shown of the Course of Events in EXPERIMENT NUMBER 59

The details are given in Table 2. 
TABLE 2

A pril 20, 1931. Dog number 59. Weight of dog-10.5 kgm. Weight of heart-90 grams. Anesthesia-Chloralose-1.15 gram

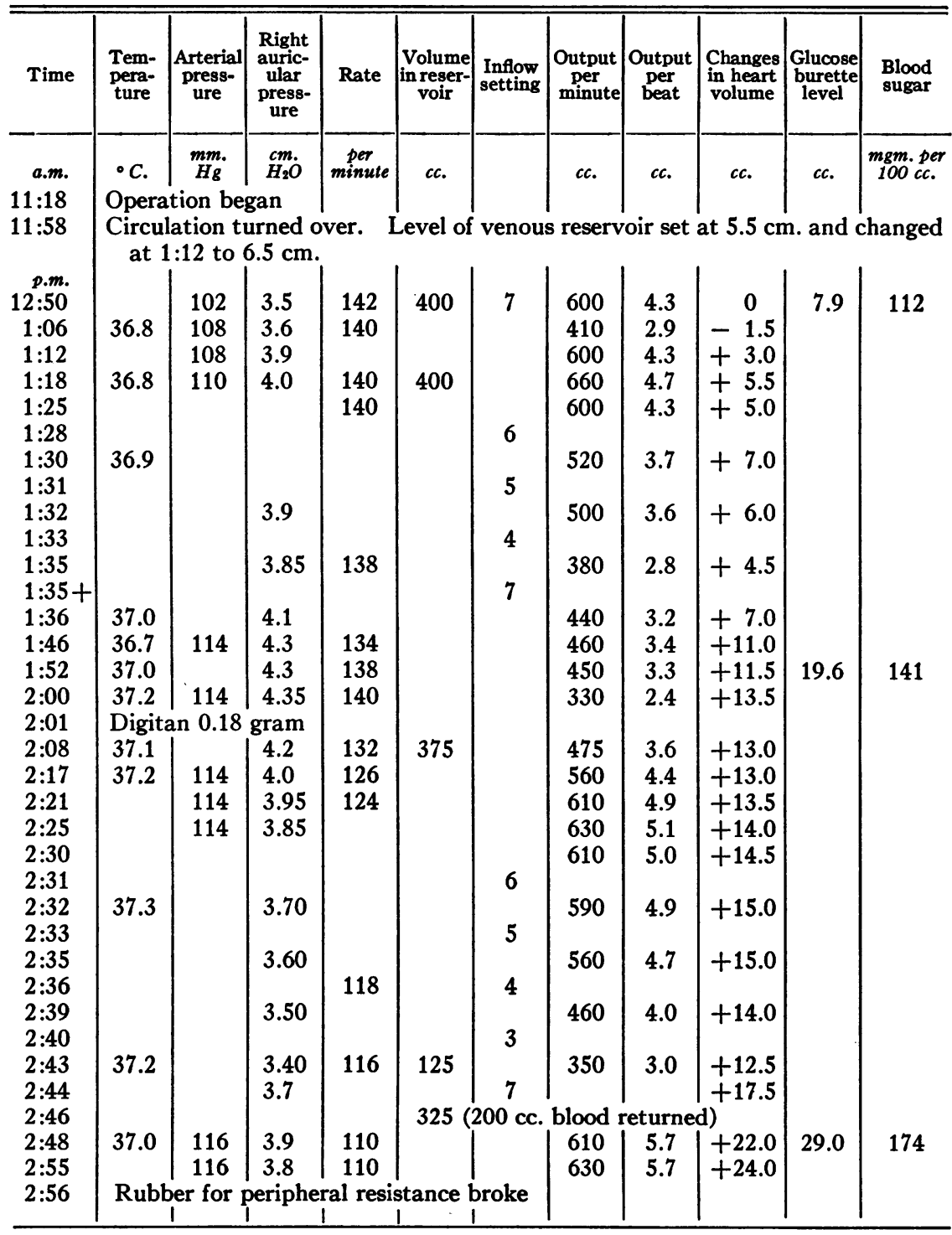

After about thirty minutes (Figure 4), the level of the venous reservoir having been set at a height of $5.5 \mathrm{~cm}$., the volume output per minute, then about $600 \mathrm{ccm}$., fell in the next ten minutes to $380 \mathrm{ccm}$. The level of the reservoir was then raised to $7.0 \mathrm{~cm}$., where it remained throughout the experiment. The output rose to about $630 \mathrm{ccm}$., higher than it had been 
before. The volume of the heart increased; the pressure in the right auricle rose. The behavior of the heart having been satisfactory for fifteen minutes, the stopcock in the inflow tube was closed bit by bit. Output per minute and per beat, pressure in the right auricle and the volume of the heart, all promptly and expectedly decreased, and decreased the more, the more nearly the stopcock was shut. After ten minutes the stopcock was again opened wide. At once, output, volume of the heart and pressure rose, but not to the initial height. The heart seemed no doubt to have been deteriorating, as is shown by its increasing volume. After another twenty minutes the preparation began seriously to fail, the output decreased to about $325 \mathrm{ccm}$., the pressure in the right auricle rose and the cardiac volume increased still further. The temperature of the blood and the rate of the heart beat remained meanwhile sufficiently steady. Digitalis was now injected. In ten minutes a substantial increase in volume output occurred and in thirty minutes the amount put out at one hour had almost been reached. The volume of the heart, which before injection had steadily been increasing, now ceased to do so; on the contrary, it became a little smaller. The pressure in the right auricle promptly declined, falling to a level lower than when the output was approximately the same as now. As the rate of the heart beat fell, the output per beat increased, so that the curve describing this function continued roughly parallel to that of the output per minute. There was, nevertheless, no increase in the heart's size. Half an hour after the injection of digitalis, the maneuver with the stopcock was repeated. The course of events noticed before took place again. The minute output and output per beat declined, the pressure fell, the heart's volume decreased. When the stopcock had been shut to a point identical (marked by asterisks on the stopcock and also on "output per minute" curves) with that before injection, it is apparent that, although the minute output just before closing the stopcock was approximately alike on both occasions, now, after the injection of digitalis, the same setting resulted in a smaller effect than before- the minute output did not decrease so much. It was greater in fact by about $80 \mathrm{ccm}$., an amount equal to 12.0 per cent of the highest output. A tighter shutting of the stopcock had, of course, a correspondingly greater effect, as the dotted line at 2.25 shows. Together with the change in minute output, corresponding changes in the volume of the heart and in right auricular pressure took place. The rate of the heart beat continued to fall so that the curve describing output per beat is higher than before. When the stopcock was opened again, the output increased to its former amount, the pressure in the right auricle also returned, but showed no disposition to rise further, evidence of the good state of the preparation. Shutting the stopcock seems, however, further to have damaged the heart for now in order to maintain its output, it dilated sharply. 
This experiment shows that: (1) Giving digitalis when the heart was in a state of acute failure, revived it, so that the initial minute output was restored. (2) Although before the administration of digitalis the heart was continuously dilating, afterward, further deterioration was arrested, until decreasing the inflow again, by shutting the stopcock, still further injured the heart. (3) Decreasing the inflow by means of the stopcock exerted a smaller effect on the minute output, after giving digitalis than it had before. Exactly how this difference is to be "explained" is not apparent. Greater contractile efficiency, decrease in rate, balanced by greater output per beat, made it possible to receive and to expel greater volumes of blood, the reservoir arrangements having remained unchanged. That the volume of flow through the heart was greater is shown by the fall of pressure in the right auricle. (4) The effect just described is characteristic of this preparation, free as it is of hepatic and all other veins save the pulmonary. The failing heart, it appears, is able, despite the decrease in inflow brought about by constriction of the veins, simulated by shutting the stopcock in this case as much as about 40 per cent, to expel more blood at the same setting under the influence of digitalis than before its administration. Inflow is in short a function not solely of the degree of constriction of the inflow tract; the state of efficiency of the heart, its ability to receive and to eject blood, is another relevant factor.

Still other experiments (the third type) were performed in dogs in which respiration was maintained by positive pressure, a $\mathrm{Y}$-shaped cannula being fixed in the trachea, the two limbs of which were connected with the inlet and outlet tubes of a Starling pump, and in which an oncometer was fitted over the heart. In an illustrative experiment (Figure 5) failure of the heart was signalled by a fall in volume output from 700

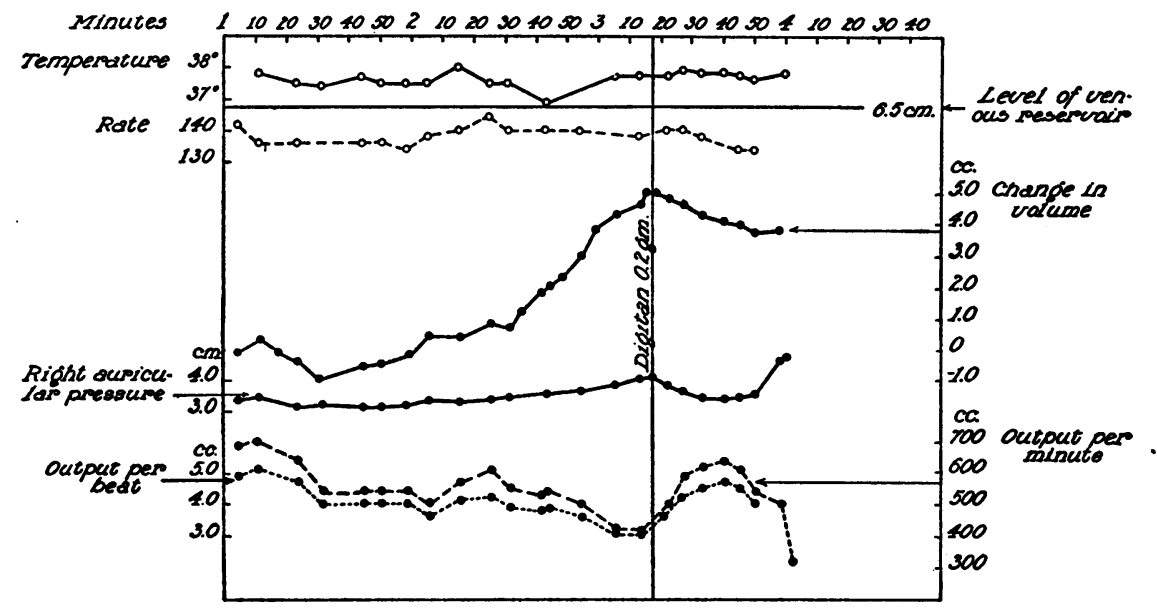

Fig. 5. The Curves are Shown of the Course of Events in EXPERIMENT NUMBER 65

The details are given in Table 3. 
TABLE 3

June 10, 1931. Dog number 65. Weight of dog-11.5 kgm. Weight of heart-109.5 grams. Anesthesia-Chloralose-1.25 gram

\begin{tabular}{|c|c|c|c|c|c|c|c|c|c|c|}
\hline Time & $\begin{array}{l}\text { Tem- } \\
\text { pera- } \\
\text { ture }\end{array}$ & $\begin{array}{c}\text { Arterial } \\
\text { press- } \\
\text { ure }\end{array}$ & $\begin{array}{c}\text { Right } \\
\text { auricular } \\
\text { pressure }\end{array}$ & Rate & $\begin{array}{c}\text { Volume } \\
\text { in reser- } \\
\text { voir }\end{array}$ & $\begin{array}{c}\text { Output } \\
\text { per } \\
\text { minute }\end{array}$ & $\begin{array}{c}\text { Output } \\
\text { per } \\
\text { beat }\end{array}$ & $\begin{array}{l}\text { Changes } \\
\text { in heart } \\
\text { volume }\end{array}$ & $\begin{array}{c}\text { Glucose } \\
\text { burette } \\
\text { level }\end{array}$ & $\begin{array}{l}\text { Blood } \\
\text { sugar }\end{array}$ \\
\hline$a . m$. & ${ }^{\circ} \mathrm{C}$. & $\underset{H g}{m m}$. & $\underset{\mathrm{H}_{2} \mathrm{O}}{\mathrm{cm}}$ & $\underset{\text { per }}{\text { minute }}$ & $c c$. & $c c$. & $c c$. & $c c$. & $c c$. & $\begin{array}{l}\text { mgm. per } \\
100 \text { ce. }\end{array}$ \\
\hline $11: 28$ & \multicolumn{10}{|c|}{ Operation began } \\
\hline $12: 21$ & \multicolumn{10}{|c|}{ Circulation turned over. } \\
\hline $1: 04$ & & 106 & 3.4 & 142 & 330 & 690 & 4.9 & $\begin{array}{l}100 \text { cc. } \\
\text { rese }\end{array}$ & $\begin{array}{l}\text { blood } \\
\text { ervoir) }\end{array}$ & added to \\
\hline $1: 11$ & 37.8 & 106 & 3.5 & 136 & & 700 & 5.1 & +0.4 & 0.1 & 82 \\
\hline $1: 23$ & 37.5 & 104 & 3.2 & 136 & 700 & 640 & 4.7 & $\mathbf{0}$ & & \\
\hline $1: 31$ & 37.4 & 104 & 3.25 & & & 540 & 4.0 & -0.9 & & \\
\hline $1: 44$ & 37.7 & 104 & 3.2 & 136 & 600 & 540 & 4.0 & -0.5 & & \\
\hline $1: 50$ & 37.5 & 104 & 3.2 & 136 & & 540 & 4.0 & -0.5 & & \\
\hline $1: 58$ & 37.5 & 104 & 3.25 & 134 & & 540 & 4.0 & -0.1 & & \\
\hline $2: 05$ & 37.5 & 104 & 3.4 & 138 & & 500 & 3.6 & +0.5 & 38.5 & 402 \\
\hline $2: 15$ & 38.0 & 106 & 3.35 & 140 & & 570 & 4.1 & +0.5 & \multicolumn{2}{|c|}{$\begin{array}{l}\text { (Blood noted in } \\
\text { pericardium) }\end{array}$} \\
\hline $2: 25$ & 37.5 & 106 & 3.4 & 144 & & 610 & 4.2 & +0.9 & & \\
\hline $2: 31$ & 37.5 & 106 & 3.5 & 140 & & 550 & 3.9 & +0.8 & & \\
\hline $2: 41$ & & & & & & 530 & 3.8 & +1.8 & & \\
\hline $2: 43$ & 36.9 & 106 & 3.6 & 140 & & 540 & 3.8 & +2.1 & & \\
\hline $2: 54$ & & 106 & 3.7 & 140 & & 500 & 3.6 & +3.1 & & \\
\hline $3: 05$ & 37.7 & 106 & 3.9 & & & 420 & 3.0 & +4.4 & & \\
\hline $3: 13$ & 37.7 & 105 & 4.1 & 138 & 200 & 410 & 3.0 & +5.1 & & \\
\hline $3: 17$ & \multicolumn{2}{|c|}{$\begin{array}{l}\text { Digitan } \\
0.2 \text { gram }\end{array}$} & 4.15 & & & & & & 48.8 & 402 \\
\hline $3: 22$ & 37.7 & 106 & 3.9 & 140 & & 500 & 3.6 & +4.9 & & \\
\hline $3: 27$ & 37.9 & 106 & 3.7 & 140 & & 590 & 4.2 & +4.7 & & \\
\hline $3: 33$ & 37.8 & 106 & 3.5 & 138 & & 620 & 4.5 & +4.4 & & \\
\hline $3: 40$ & 37.8 & 106 & 3.45 & & & 640 & 4.7 & +4.2 & & \\
\hline $3: 45$ & 37.7 & 106 & 3.5 & 134 & & 610 & 4.5 & +4.1 & & \\
\hline $3: 50$ & 37.6 & 106 & 3.6 & 134 & & 540 & 4.0 & +3.9 & 52.3 & 436 \\
\hline $3: 58$ & & & 4.7 & & & 500 & $?$ & & & \\
\hline $4: 00$ & 37.8 & & 4.8 & & & 310 & & & & \\
\hline
\end{tabular}

ccm. to $410 \mathrm{ccm}$. per minute. The heart dilated, the venous pressure rose. Important changes did not take place in the pulse rate or in the temperature. When digitalis was injected, the minute output rose to almost its original level. There was prompt and striking decrease in its volume, the decrease continuing for a short time after the maximum output was attained. In all probability, the pericardium being open, the heart even then was relatively dilated, in comparison with its original, natural size. The change illustrates the fact, however, that, when heart muscle fibers are stretched more than a certain length, shortening does not, as is the case of normal hearts, decrease but rather increases the minute output. Coincident with the rise in output, occurred a distinct 
fall in right auricular pressure. The rate of the heart beat also fell but only six a minute.

Propelling blood against more than an atmosphere of intrapulmonary pressure did not in this experiment interfere with the ability of the heart to increase its output when digitalis was administered. It is striking, furthermore, how great were the concomitant effects on the size of the beat and on the pressure in the right auricle. Despite decrease in volume, the output was increased to so great an extent that it was able to receive blood and to propel it onward toward the lungs so competently as to lower the pressure in the right auricle very considerably.

Twenty-three experiments in all are reported. In one-half the final effect of the action of digitalis was to decrease the rate of the heart, though in one-half of these, the fall was preceded by a slight rise. In two experiments only did the rate increase promptly and permanently. In the remainder it remained practically constant. These statements refer only to rates during periods of normal cardiac mechanism. As terminal phenomena, paroxysms of ventricular tachycardia were frequently observed, and on a few occasions recoveries from paroxysms, in early stages. In no instance did the rate of the heart beat change sufficiently so that alterations in it could be regarded seriously as responsible, during the period of the action of digitalis, for altering the cardiac minute output.

Five experiments were valueless for the purpose of securing measurements of venous pressure, of cardiac output and of changes in size of the heart. In one case (Number 63) clots formed in the circulating blood; in two others (Numbers 52 and 60) large hemorrhages took place in the cardiometer; and in two additional ones (Numbers 55 and 57) ventilation under negative pressure failed. The two cases last mentioned are, however, not without interest. Although they cannot yield measurements comparable with those found in other instances, they do, nevertheless, suggest reasons which explain the failure of the action of digitalis (Table 4).

The remaining eighteen experiments (Table 4) were sufficiently satisfactory to permit deductions to be made from the measurements. In all of them, the temperatures and the rate of the heart beat were approximately constant; these factors need, therefore, not to be taken further into consideration. The venous reservoir remained at a constant level after it was definitely set. Since the pressure level of the "peripheral resistance" varied within slight limits only during the course of an experiment, changes in brachiocephalic blood pressure did not occur. For these reasons, the following six variable factors only require study: (1) the minute output from the heart, (2) the size of the heart, (3) the pressure in the right auricle, (4) the condition of the heart, (5) the condition of the lungs, and finally (6) the condition of the blood which is in turn dependent on the state of the lungs and the rate and volume of the blood 
flow. Since experiments showing gross changes in the lungs and in the blood were not further studied, the last two factors (5) and (6) may be ignored. There remain, therefore, only four variable factors. The first three can all be measured and since in fact they are dependent on the condition of the heart, measurement of them describes in turn the state of this organ. Changes in these measurements depend, therefore, upon changes in the heart. It should be possible, consequently, by comparing measurements made before giving digitalis with others made afterwards, to describe certain of the effects for which the administration of this drug is responsible (Table 4). Descriptions of three typical courses of events have been given already. The following description may serve, therefore, as a general summary.

When the pressure in the right auricle rose slowly and steadily, the volume output per minute and per beat decreased, and the size of the heart simultaneously increased. A cardiometer was employed in ten only of the experiments. In one case (Number 60) a leak of air invalidated the results. But in the other nine instances, measurements made it certain that the hearts dilated. In the eight cases in which an oncometer was not used, it seems certain also that the hearts increased in size.

The effect of the administration of digitalis was prompt and definite as measured by the three criteria on which reliance was placed: the minute output, having fallen, rose; the pressure in the right auricle, having risen, fell; the heart, having dilated, contracted. These results were noticed in fourteen of the eighteen satisfactory experiments. Of the remaining four, one (Number 57) only showed no effect, but in the other three (Numbers $49,52,55)$ the effects were either slight or their progress having begun was promptly halted so far as concerns reduction in size of the heart and rise in right auricular pressure, though in all three the output exhibited a slight rise.

\section{DISCUSSION}

These experiments, it seems, supply evidence which shows that hearts which are obviously failing, in that, although constantly increasing in size they are expelling ever smaller volumes of blood can, nevertheless, as a consequence of receiving digitalis, deliver greatly increased quantities. Since there are no blood vessels, except the bronchial and pulmonary vessels, nor any other structures in the preparation than the lungs, no other mechanism can be responsible for this occurrence than the heart itself. The heart can apparently become smaller and at the same time more efficient in increasing the volume of blood which it expels. That an effect of the action of digitalis is exercised on heart muscle is well known, and also that this effect may consist at one stage in increasing the degree of its systolic contraction. Experiments have shown in fact that "improvement" in the behavior of the heart takes place also in damaged and 
TABLE 4

A summary of the individual experiments in the three groups

\begin{tabular}{|c|c|c|c|c|c|c|c|c|c|}
\hline$\underset{\text { ber }}{\text { Dog }}$ & $\begin{array}{l}\text { Change } \\
\text { of tem- } \\
\text { pera- } \\
\text { ture }\end{array}$ & Rate & $\begin{array}{c}\text { Right } \\
\text { auric- } \\
\text { ular } \\
\text { pressure }\end{array}$ & $\begin{array}{l}\text { Volume } \\
\text { output } \\
\text { per } \\
\text { minute }\end{array}$ & $\begin{array}{l}\text { Volume } \\
\text { output } \\
\text { per } \\
\text { beat }\end{array}$ & $\begin{array}{c}\text { Change } \\
\text { in volume } \\
\text { of } \\
\text { heart }\end{array}$ & $\begin{array}{l}\text { Dura- } \\
\text { tion } \\
\text { after } \\
\text { digitan }\end{array}$ & Dose & Constriction of inflow \\
\hline & - $C$. & $\begin{array}{c}\text { per } \\
\text { minute }\end{array}$ & $\stackrel{\mathrm{cm}}{\mathrm{H}_{2} \mathrm{O}}$ & $c c$. & cc. & $c c$. & $\begin{array}{l}\text { min- } \\
\text { utes }\end{array}$ & grams & \\
\hline
\end{tabular}

Group I. Negative pressure, no oncometer

\begin{tabular}{l|c|c|c|c|c|c|c|c|c}
\hline 36 & 0 & 128 & +0.4 & 290 & 2.4 & & 30 & 0.5 & \\
\hline 37 & 0 & 138 & -1.2 & 200 & 1.4 & & 20 & 0.3 & \\
& & 142 & -4.0 & 470 & 3.4 & & & & \\
\hline 38 & 0 & 138 & + & 90 & & & 40 & 0.3 & \\
& & 114 & - & 240 & + & & 10 & 0.1 & \\
\hline 39 & 0 & 146 & +2.2 & 240 & & & 30 & 0.3 & \\
& & 126 & -1.0 & 920 & + & & & & \\
\hline 41 & 0 & 144 & +0.8 & 200 & & & 55 & 0.25 & \\
\hline 42 & 0 & 118 & -3.6 & 200 & & & 65 & 0.25 & \\
\hline 44 & 0 & 140 & +2.4 & 230 & 1.6 & & 70 & 0.25 & \\
\hline 45 & 0 & 166 & -2.0 & 510 & + & & & & \\
\hline & & 186 & $-?^{*}$ & $760^{* *}$ & 4.1 & & & & \\
\hline
\end{tabular}

Group II. Negative pressure, with oncometer

\begin{tabular}{l|c|c|c|c|c|c|c|c|c}
\hline 49 & +1.2 & $\begin{array}{c}134 \\
138\end{array}$ & $\begin{array}{l}+20 \\
+20\end{array}$ & $-?^{*}$ & $-?^{*}$ & $\dagger$ & 37 & 0.25 & \\
\hline 50 & -1 & $\begin{array}{c}140 \\
168\end{array}$ & +4.4 & 690 & 4.6 & & 44 & 0.25 & \\
\hline 51 & 0 & 154 & +7.2 & 1070 & 6.1 & -1 & & & \\
\hline 52 & 0 & 136 & +6.0 & $700^{* *}$ & $+?$ & -8 & 35 & 0.25 & \\
\hline
\end{tabular}

$\ddagger$ Whenever two figures appear in a space the upper represents the value recorded immediately before the administration of digitalis, the lower the maximum effect of the drug.

* Continual decrease during the experiment.

** Continual increase during the experiment.

† Oncometer leaked. 
TABLE 4 (continued)

\begin{tabular}{|c|c|c|c|c|c|c|c|c|c|}
\hline$\underset{\substack{\text { num- } \\
\text { ber }}}{\text { Dog }}$ & \begin{tabular}{|c|} 
Change \\
of tem- \\
pera- \\
ture
\end{tabular} & Rate & $\begin{array}{c}\text { Right } \\
\text { auric- } \\
\text { ular } \\
\text { pressure }\end{array}$ & $\begin{array}{l}\text { Volume } \\
\text { output } \\
\text { per } \\
\text { minute }\end{array}$ & $\begin{array}{c}\text { Volume } \\
\text { output } \\
\text { per } \\
\text { beat }\end{array}$ & $\begin{array}{c}\text { Change in } \\
\text { volume } \\
\text { of } \\
\text { heart }\end{array}$ & $\begin{array}{c}\text { Dura- } \\
\text { tion } \\
\text { after } \\
\text { digitan }\end{array}$ & Dose & Constriction of inflow \\
\hline 53 & $\begin{array}{l}C . \\
0\end{array}$ & $\begin{array}{c}\text { per } \\
\text { minute } \\
136 \\
128\end{array}$ & $\begin{array}{c}\quad c m . \\
\mathrm{H}_{2} \mathrm{O} \\
+\quad 7.8 \\
+\quad 7.2\end{array}$ & $\begin{array}{l}c c . \\
310 \\
500\end{array}$ & $\begin{array}{l}c c . \\
+\end{array}$ & $c c$ & $\begin{array}{r}\underset{\text { unes }}{\min } \\
24\end{array}$ & $\begin{array}{c}\text { grams } \\
0.20\end{array}$ & \\
\hline 54 & -0.7 & $\begin{array}{l}120 \\
116\end{array}$ & $\begin{array}{l}+8.9 \\
+9.0\end{array}$ & $\begin{array}{l}290 \\
470\end{array}$ & $\begin{array}{l}2.6 \\
4.4\end{array}$ & $\S$ & 87 & 0.15 & $\begin{array}{l}\text { - } 80 \text { cc. } \\
\text { - } 19.5 \text { per cent } \\
\text { No reduction }\end{array}$ \\
\hline 55 & +1.7 & $\begin{array}{l}126 \\
112\end{array}$ & $\begin{array}{l}+4.7 \\
+4.8\end{array}$ & $\begin{array}{l}260 \\
270\end{array}$ & $?$ & $+?$ & $\begin{array}{r}36 \\
5\end{array}$ & $\begin{array}{l}1.5 \\
0.1\end{array}$ & \\
\hline 56 & 0 & $\begin{array}{l}140 \\
104\end{array}$ & $\begin{array}{l}+11 \\
+10.6\end{array}$ & $\begin{array}{l}300 \\
580\end{array}$ & + & -5 & 73 & 0.2 & $\begin{array}{l}-270 \mathrm{cc} . \\
-45 \text { per cent } \\
-210 \mathrm{cc} . \\
-36 \text { per cent }\end{array}$ \\
\hline 57 & 0 & $\begin{array}{l}134 \\
134\end{array}$ & $\begin{array}{l}+4.0 \\
+4.0\end{array}$ & $\begin{array}{l}340 \\
300^{*}\end{array}$ & $-?$ & - $^{* * *}$ & 35 & 0.18 & $\begin{array}{l}\text { Reduced } \\
\text { Not done }\end{array}$ \\
\hline 59 & 0 & $\begin{array}{l}140 \\
110\end{array}$ & $\begin{array}{l}+8.7 \\
+7.7\end{array}$ & $\begin{array}{l}330 \\
630\end{array}$ & $\begin{array}{l}2.4 \\
5.1\end{array}$ & $-1 \S$ & 56 & 0.18 & $\begin{array}{l}-220 \mathrm{cc} . \\
-36.7 \text { per cent } \\
-150 \mathrm{cc} . \\
-26.0 \text { per cent }\end{array}$ \\
\hline 60 & 0 & $\begin{array}{l}134 \\
132\end{array}$ & $+? ?^{* *}$ & $\begin{array}{l}360 \\
300^{*}\end{array}$ & $-?$ & $-? \dagger$ & 25 & 0.18 & $\begin{array}{l}\text { Reduced } \\
\text { Not done }\end{array}$ \\
\hline
\end{tabular}

Group III. Positive pressure, with oncometer

\begin{tabular}{l|c|c|c|c|c|c|c|c|c}
\hline 63 & -1.5 & 134 & +9.0 & 320 & & $\dagger$ & 34 & 0.18 & \\
& & 130 & +8.0 & 370 & $+?$ & & & & \\
\hline 64 & 0 & 148 & +9.8 & 390 & & & 48 & 0.2 & \\
& & 150 & +9.0 & 460 & + & $-6.0^{*}$ & & & \\
\hline 65 & 0 & 138 & +8.3 & 410 & & & 45 & 0.2 & \\
& & 134 & +6.9 & 640 & + & -1.2 & & & \\
\hline 66 & 0 & 128 & +14.2 & 300 & & & 63 & 0.2 & \\
\hline
\end{tabular}

$\S$ Further increase in size postponed for varying periods of time although no decrease occurred.

*** After revival by positive pressure. 
feeble hearts. But these experiments supply evidence not only that damaged and feeble hearts can be so influenced but also that hearts which are dilated can. And they show, furthermore, that when they expel greater volumes, they may at the same time diminish in size. Smaller hearts manage, in short, to increase the volume output.

This situation is different from that in hearts which, because obviously undamaged, are of normal size and in certain other hearts which are damaged but are not dilated, even as the result of forced exercise (Harrison and Leonard (1), Cohn and Stewart(2)). The hearts which were studied in the experiments now reported were plainly not fresh hearts. To draw inferences from their use, as if they were, would be unjustified. But the point at issue has not to do with whether they were fresh or old, but essentially with whether the effect of digitalis is exerted in a significant fashion on the heart muscle, and with what that effect is. If its action on enlarged hearts, dilated or hypertrophied, is admitted, but an effect on normal sized hearts is denied, a point in the process of lengthening must be found at which the muscle begins to be susceptible to the action of the drug. There may be such a point, but its presence has not, so far, been the subject of investigation. The volume outflow may under definite circumstances reflect the action of other influences. But to arrive at a complete description, it is not enough to study only the peripheral action of digitalis. Its cardiac action has consequently been investigated in detail. In other experiments, to attempt to ascertain what effect on the net result might be contributed by an action on the peripheral circulation, especially in the portal and hepatic regions, the stopcock was placed in the inflow tract to the heart. Reference will be made to this type of experiment later.

The decrease in volume output which has been noticed was thought to result from the tonic effect of digitalis upon the heart (2), in consequence of which its size diminished so much, that a large or even a usual volume of blood could not be received and, therefore, could not be ejected. Dock and Tainter $(3,4)$ believe that an explanation of this sort must be rejected because it fails to take into account the behavior of the rest of the circulatory apparatus which, as they think, is simultaneously affected. They have drawn attention (4) to a mechanism in the hepatic veins by which, under the influence of digitalis, the lumina, the walls containing smooth muscle which contracts, diminish and prevent the return of blood to the heart (10) because it is dammed back into the intestinal cavity. The decrease in output from the heart results accordingly not from a primary effect upon the dimensions of the heart but from a secondary one due to constriction of the hepatic veins. The heart becomes small, not because of the effect upon it of the action of digitalis but because it can not be filled.

Now the vessels which transfer blood from the descending aorta to 
the inferior vena cava may be said to consist of a main circuit, returning blood chiefly from the kidneys, the pelvis and the legs; and a shunt which conveys blood to the intestinal viscera, chiefly to the spleen, the pancreas and the intestines, and which then passes through the liver, entering the inferior vena cava finally through the hepatic veins. The blood flowing into the right auricle is derived both from the superior and the inferior vena cava and the vena azygos. The portion which the hepatic veins contribute to the inferior vena cava is, as Grab, Janssen and Rein have shown (11) approximately 50 to 60 per cent or about one quarter of the amount which flows to the right auricle. On occasion this amount may be augmented to about 80 per cent or about one third of the total.

It seems to be a fact that not only individuals, but species vary considerably in the amount of smooth muscle which the walls of the hepatic veins contain. On this, when present, digitalis acts. In consequence of this action, the smooth muscle contracts and by so doing narrows the lumen so that blood is dammed back in the portal system. That this result occurs, especially in dogs, is known because the pressure in the portal system rises but the extent of the pooling, important in the mechanism only if great, is not known. But, as recent investigations have shown (12) it is dogs especially which exhibit this anatomical peculiarity. The hepatic veins of cats, for example, and of human beings fail to exhibit conspicuous amounts of the smooth muscle. Whatever may be the case regarding the mechanism in question in dogs, it cannot be operative in human beings because plainly it does not exist in them to a significant degree.

But in a given dog the possibility of the existence of this mechanism remains, capable of reducing the return flow to the heart to an extent so great that the total volume inflow and in consequence the size of the heart are reduced on this account to the extent that observation shows them to be.

The anatomy of the hepatic veins themselves requires, however, close scrutiny. They can, as has been said, be responsible for conveying $\mathbf{5 0}$ per cent of the blood which flows back into the inferior vena cava. They are in short each, right and left hepatic veins, large structures. Their united circumference exceeds that of the inferior vena cava (13). In order to be effective in shutting off from the volume of blood returning to the right auricle as much as a quarter, the lumina of the two vessels must be reduced to zero-must be completely obliterated. What the facts are is not known. The muscle in the walls of the hepatic veins, though abundant, seems scarcely capable of so powerful an action. But if they cannot close wholly they may conceivably close as much as $\mathbf{5 0}$ per cent. If they manage this, they deprive the inflow to the auricle of one-eighth (12 per cent) only of its total volume. And even if they succeed in bringing about this result, the diminution should be incapable of explaining 
the facts found in earlier experiments $(2 a)$. The results that were found in those dogs were striking. The outflow decreased not 12 per cent but in amounts varying between 34 and 68 per cent (with one exception in which it was only 14 per cent Table 5A). These are the consequences of giving

\section{TABLE 5}

The effect of digitalis on the cardiac output in dogs with normal hearts $(A)$ and with enlarged hearts, the result of artificial valvular lesions of long standing $(B) . *$

\begin{tabular}{c|c|c|c}
\hline \multicolumn{2}{|c|}{ A. } & \multicolumn{2}{|c}{ B. } \\
\hline Dog number & Per cent decrease & Dog number & Per cent decrease \\
\hline 265 & 66 & 162 & 58 \\
257 & 38 & & 67 \\
258 & 48 & 161 & 32 \\
253 & 46 & 158 & 62 \\
254 & 45 & & 31 \\
252 & 35 & 155 & 65 \\
251 & 53 & 171 & 47.4 \\
255 & 34 & 90 & 44 \\
264 & 14 & & 23 \\
259 & 50 & & \\
261 & 68 & & \\
263 & 47 & & \\
\hline
\end{tabular}

* The data in this table are taken from the tables in papers by Cohn and Stewart $(2 a$ and $b)$.

digitalis to dogs, the hearts of which were normal. When similar experiments were attempted in the dogs in which the hearts were enlarged (hypertrophied) $(2 b)$ as the result of long standing damage to the mitral valves, the reduction in output was at least as great as in the normal ones and in some cases even greater (Table 5B). To refer the explanation of decreased outflow to decreased inflow-due to contraction of the hepatic and mesenteric veins seems, therefore, incorrect.

But this explanation of the mechanism of diminished outflow seems unlikely for other reasons as well. The effect of the action of digitalis upon the heart endures for days. There are records (Cohn and Stewart) of the persistence of the action as long as 10 days; and durations of 3 days are not uncommon. In human beings all the effects have often not disappeared even after $\mathbf{2 1}$ days. In comparison with durations as long as these, those reported on the length of time the effect of the action of digitalis has been observed on the hepatic veins must be regarded as evanescent. Unfortunately no example is shown (Tainter and Dock) in which the effect persisted longer than 25 minutes or, when digitalis and strophanthin were given in succession, for longer than $\mathbf{4 0}$ minutes. The observations were then terminated. If rise in pressure in the portal 
system is taken as the duration of the action of these drugs on the hepatic veins, 5 to 12 or 15 minutes seems to be the maximum period. If the criterion is fall of pressure in the right auricle, this effect did not occur in Dog 1, began to disappear in Dog 2 after 14 minutes, and in Dog 4, after giving strophanthin, had regained its initial level in 20 minutes. It lasted somewhat longer, for 2 hours, in Dogs F4 and F5, when the records stop. The constrictor action of digitalis on the hepatic veins occurs, no doubt. When it fails to do so in Dog 1, the hepatic veins may be poor in muscle. Interesting though this action is, it seems to be transient. A point of importance should be made on the matter of the duration of effect. If, as between effect on heart and on hepatic veins, that on veins persists, it is essential to know in general how long this action may be. That on the heart is known to last for several, perhaps for many days. If that on the veins is as long, the action of both structures must contribute to the final result; if not, that on the veins possesses a slight influence only. The evidence concerning the effect on the veins so far assembled is meagre.

In intact dogs ( $2 a$ and $b)$ the effect of injection was studied 2 to 3 hours after injecting digitalis, except in two instances when the times given are $1 \frac{1}{2}$ to $1 \frac{3}{4}$ hours. And the persistence of the action is not minutes but 1 to 3 to 10 days. If, as seems to be the fact, the hepatic veins become narrow, the duration of this influence of digitalis is so brief that there must be hesitation in attributing to this effect of the drug, responsibility for the long persisting decrease in outflow, a decrease which does not begin to be effective, or at all events did not begin to be studied, until 2 hours (2a) after injection, and which persists for many days. The hepatic mechanism is plainly non-existent in any important sense. If objection is made to ignoring the short duration of the effect of digitalis on the heart in heart-lung experiments and to insisting upon it in connection with experiments on the hepatic and splanchnic veins, it may be pointed out that the two experiments differ. Those on the heart come to an end not because the action of digitalis ceases, but because it proceeds often to still greater and graver damage. The effect on the veins ceases because in all probability it is overshadowed by the results of trauma. Whether its action persists, nevertheless, is unknown. In intact animals the situation is different; the duration of the effect is longer but it has not been observed beyond two hours.

To test the relation of low venous pressure to decreased minute output, those experiments were performed in which the calibrated stopcock was inserted in the inflow tract. The pressure in the right auricle rose, as has been described, when the heart began to fail; it fell when the heart revived. There can be no question in these experiments of a venous (hepatic) mechanism; there were no veins. Nor can there have been any change in the volume of blood to which the heart had access; the amount, 
due to the arrangement of the experiment was always the same. If a change in pressure took place, as it did, the behavior of the heart alone must have been responsible. And this change, a fall in pressure in the right auricle, it was able to bring about even when, and this point is not without interest, a decrease in its size took place. Decrease in the return flow is not the condition, obviously, which is responsible either for decrease in the size of the heart, for the outflow increased, or for the fall in pressure in the right auricle, because there was no decrease in the volume of blood ready to flow in.

A further test could be made of the possible influence of constricted hepatic veins on the net result of giving digitalis, so far as output is concerned. It has already been suggested that the maximum effect likely to take place as the result of constriction of the hepatic veins due to giving digitalis is a reduction in inflow of about 12 per cent. If the veins were shut entirely the effect, an unlikely occurrence, would be 25 per cent. When the heart in the experiments now reported began to fail, the cock to which reference has been made was partially shut, so that volumes less than the initial ones were available to the heart. Reductions in caliber greater than 10 per cent effected a reduction in output but, and this is the point, the reduction in output at identical settings of the stopcock was greater in the undigitalized failing, than it was in the digitalized, heart. Giving digitalis may constrict the hepatic veins so that the output from the heart is diminished but, as this experiment shows, this is a consequence depending not simply on the degree of constriction of the veins but on the difference in the heart after giving digitalis. The dilated failing heart can, from the same reduced inflow path, manage a greater output; and in the intact animal when the entrance pathway is reduced to 75 to 87 per cent, the heart can still deliver a greater volume than before.

But for the normal heart the restriction in inflow cannot, as has been shown, represent the facts. Proof that this must be the mechanism on which decreased size of the heart and decreased output depend has been believed (4) to depend on the low level of venous pressure. Evidence beyond that found in these experiments, which describe the course of events in failing hearts, to show that low venous pressure and small size together with diminished output, as is found in normal hearts, are not in necessary relation, is supplied in a study of the action of digitalis in normal human beings. It is undesirable to anticipate the report (14) which describes such observations, but mention may be made now of the fact that, in them, measurement of the venous pressure fails to show, on the assumption which has been made, that this function of the circulation behaves in a way capable of explaining the facts.

${ }^{4}$ Those experiments in which the volume of the inflow is varied by changing the level of the reservoir are obviously different. In them the head of pressure remains constant. 
An effect on the tone of the heart appears to be, in the light of these considerations, the outstanding phenomenon. And by tone is meant the diastolic size of the heart, for this in a given case is indicative of the length of fiber, the length of fiber being, in turn, "synonymous with physiological condition or fitness of the muscle fibre" (Patterson, Piper and Starling (15)). This, as Bodo (16) remarks, was correlated by Starling and Visscher (17) with the oxygen consumption of the heart and the consumption of this "was determined by the initial length of its muscular fibres, i.e. by its diastolic volume." The heart's tone may be measured, therefore, in terms of its diastolic volume, "provided that the work performed by the heart is maintained constant during the whole of the experment." Since, in the experiments of Cohn and Stewart the measurements were made during periods when the dogs were in so-called basal states, the work which their hearts performed may be regarded as constant, and the effects on diastolic' size, as measures of the effect of the action of digitalis on tone. In the current experiments the situation is different. The amount of work which the hearts did, and the rate of the contractions varied, as well as the output per beat, although the resistance against which they worked was uniform. These were the effects which took place with deterioration of the preparation and they may be regarded as measures of the decrease in its effectiveness, expressed ultimately as increase in its diastolic size. If change in diastolic size is expressive of change in tone, change in tone took place in these experiments as well as in the ones formerly reported $(2 a, b)$ (Cohn and Stewart).

\section{CONCLUSIONS}

1. The minute output from failing, dilated hearts in dogs in heart lung preparations is increased when "therapeutic" doses of digitalis are administered. This effect is the opposite of that in the case of healthy hearts, normal in size.

2. When the output increases, the pressure in the right auricle decreases.

3. Increase in output is consistent with decrease in the diastolic volume of the heart.

4. If the inflow, and consequently the outflow, from the heart is restricted, the decrease in outflow is greater in the failing heart than in the same heart when it acts under the influence of digitalis. It appears from this test and from the discussion in the text that constriction of the hepatic veins is not a significant factor in the effect which the action of digitalis exerts on the size of the failing heart.

5. In estimating the value of a drug, its usefulness in therapeutics need not depend on its effect of any given function which presumably is correlated with the effect of that drug on the organism as a whole. 
Addendum: After the completion of this report, the investigations of W. Bauer, H. H. Dale, L. T. Poulsson, and D. W. Richards, on "The control of the circulation throught the liver" (J. Physiol., 1932, lxxiv, 343) appeared. A throttle mechanism in the livers of dogs was found to exist, but not one in cats and goats. Species obviously vary markedly in the possession of this function. Even when present, as in dogs, its influence depends on many factors, including constriction or dilatation of splanchnic vessels so that inferences in other connections, as for example its effect on the accumulation of blood in the abdominal vessels, apart from direct experiment, should not be drawn.

\section{BIBLIOGRAPHY}

1. Harrison, T. R., and Leonard, B. W., J. Clin. Invest., 1926, iii, 1. The Effect of Digitalis on the Cardiac Output of Dogs and Its Bearing on the Action of the Drug in Heart Disease.

2. (a) Cohn, A. E., and Stewart, H. J., J. Clin. Invest., 1928, vi, 53. The Relation between Cardiac Size and Cardiac Output per Minute Following the Administration of Digitalis in Normal Dogs.

(b) Cohn, A. E., and Stewart, H. J., J. Clin. Invest., 1928, vi, 79. The Relation between Cardiac Size and Cardiac Output per Minute Following the Administration of Digitalis in Dogs in Which the Heart is Enlarged.

3. Dock, W., and Tainter, M. L., J. Clin. Invest., 1930, viii, 467. The Circulatory Changes after Full Therapeutic Doses of Digitalis with a Critical Discussion of Views on Cardiac Output.

4. Tainter, M. L., and Dock, W., J. Clin. Invest., 1930, viii, 485. Further Observations on the Circulatory Actions of Digitalis and Strophanthus with Special Reference to the Liver, and Comparisons with Histamine and Epinephrine.

5. Anitschkow, S. W., and Trendelenburg, P., Deutsche med. Wchnschr., 1928, liv, 1672. Die Wirkung des Strophanthins auf das suffiziente und auf das insuffiziente Warmblüterherz.

6. Bijlsma, U. G., and Roessingh, M. J., Arch. f. exper. Pathol. u. Pharm., 1922, xciv, 235. Die Dynamik des Säugetierherzens unter dem Einfluss von Stoffen der Digitalisgruppe.

7. Plant, O. H., J. Pharm. and exper. Therap., 1913-14, v, 603. A Note on the Efficiency of the Knowlton-Starling Isolated Heart-Lung Preparation for Testing the Cardiac Action of Drugs.

8. Knowlton, F. P., and Starling, E. H., J. Physiol., 1912, xliv, 206. The Influence of Variations in Temperature and Blood-pressure on the Performance of the Isolated Mammalian Heart.

9. Bayliss, L. E., Müller, E. A., and Starling, E. H., J. Physiol., 1928, lxv, 33. The Action of Insulin and Sugar on the Respiratory Quotient and Metabolism of the Heart-Lung Preparation.

10. Lampe, W., and Méhes, J., Arch. f. exper. Pathol. u. Pharm., 1926, cxvii, 115. Gefässstudien an der überlebenden Warmblüterleber. II. Die Beeinflussung der Lebergefässe durch Strophanthin und Digitalisglykoside.

11. Grab, W., Janssen, S., u. Rein, H., Ztschr. f. Biol., 1929, lxxxix, 324. Ueber die Grösse der Leberdurchblutung. 
12. Popper, H., Klin. Wchnschr., 1931, x, 2129. Über Drosselvorrichtungen an Lebervenen.

13. Elias, H., und Feller, A., Stauungstypen bei Kreislaufstörungen mit besonderer Berücksichtigung der exudativen perikarditis. Julius Springer, Wien. u. Berlin, 1926.

14. Stewart, H. J., and Cohn, A. E., J. Clin. Invest., 1932, xi, 917. Studies on the Effect of the Action of Digitalis on the Output of Blood from the Heart. III. Part 1. The Effect on the Output in Normal Human Hearts. Part 2. The Effect on the Output of Hearts in Heart Failure with Congestion in Human Beings.

15. Patterson, S. W., Piper, H., and Starling, E. H., J. Physiol., 1914, xlviii, 465. The Regulation of the Heart Beat.

16. Bodo, R., J. Physiol., 1928, lxiv, 365. The Effect of the "Heart-tonics" and Other Drugs upon the Heart-tone and Coronary Circulation.

17. Starling, E. H., and Visscher, M. B., J. Physiol., 1927, 1xii, 243. The Regulation of the Energy Output of the Heart. 